\title{
Fatty acids, lipid and protein oxidation, metmyoglobin reducing activity and sensory attributes of biceps femoris muscle in goats fed a canola and palm oil blend
}

\author{
K.D. Adeyemi ${ }^{1,6}$, M. Ismail $^{1}$, M. Ebrahimi ${ }^{4}$, A.B. Sabow ${ }^{1,7}$, \\ R.M. Shittu ${ }^{5}$, R. Karim ${ }^{5}$ \& A.Q. Sazili, ${ }^{1,3 \#}$ \\ ${ }^{1}$ Department of Animal Science, Faculty of Agriculture, ${ }^{2}$ Halal Products Research Institute, ${ }^{3}$ Laboratory of Animal \\ Production, Institute of Tropical Agriculture. ${ }^{4}$ Department of Veterinary Preclinical Sciences, Faculty of Veterinary \\ Medicine, ${ }^{5}$ Department of Food Technology, Faculty of Food Science and Technology, Universiti Putra Malaysia, 43400 \\ UPM Serdang, Selangor, Malaysia, ${ }^{6}$ Department of Animal Production, University of Ilorin, PMB 1515 Ilorin, Nigeria. \\ Department of Animal Resource, University of Salahaddin, Erbil, Kurdistan Region, Iraq
}

(Received 8 June 2014; Accepted 9 September 2015; First published online 23 May 2016)

\author{
Copyright resides with the authors in terms of the Creative Commons Attribution 2.5 South African Licence. \\ See: http://creativecommons.org/licenses/by/2.5/za \\ Condition of use: The user may copy, distribute, transmit and adapt the work, but must recognise the authors and the South African \\ Journal of Animal Science.
}

\begin{abstract}
The link between the consumption of saturated fatty acids of ruminant meat and the incidence of chronic diseases in humans substantiates efforts to modify its lipid profile. However, altering the lipid profile of ruminant meat could affect its quality attributes and shelf life. This study investigated the effect of a blend of $80 \%$ canola oil and $20 \%$ palm oil (BCPO) and post mortem ageing on lipid composition, antioxidant status, colour, metmyoglobin reducing activity (MRA) and lipid and protein oxidation in biceps femoris muscle in goats. Twenty-four bucks were randomly assigned to diets containing on a dry matter basis, $0 \%, 4 \%$ or $8 \%$ $\mathrm{BCPO}$, fed for $100 \mathrm{~d}$, and slaughtered. The biceps femoris was subjected to $7 \mathrm{~d}$ post mortem ageing $\left(4^{\circ} \mathrm{C}\right)$. Neither diet nor post mortem ageing altered catalase, superoxide dismutase and glutathione peroxidase activities or sensory attributes of the biceps femoris. Dietary BCPO improved $\alpha$ - and $\mathrm{y}$-tocopherol, but did not affect total carotenoids and $\delta$-tocopherol, colour, metmyoglobin content, MRA, TBARS, carbonyl content and free thiol content. Goats fed 4\% BCPO had higher cis-9 trans-11 CLA, while those fed 8\% BCPO had higher C18:3n-3 and C20:5n-3 compared with other treatments. The 4\% and 8\% BCPO meat had lower C14:0, but higher $\mathrm{C} 18: 1 \mathrm{n}-9$ and $\mathrm{C} 22: 5 \mathrm{n}-3$ than the control goats. Post mortem ageing decreased muscle polyunsaturated fatty acids (PUFA), antioxidant compounds, redness, MRA and oxidative stability of lipid and proteins, but increased metmyoglobin content. Dietary BCPO enhanced beneficial muscle lipids without compromising the sensory quality, and lipid and protein stability of the goat meat.
\end{abstract}

Keywords: Antioxidants, carbonyl, fatty acids, metmyoglobin, thiol

\# Corresponding author: awis@upm.edu.my

\section{Introduction}

Ruminant meat has long been a sought-after source of nutrients in human diets. Its nutrient-dense composition of protein, fats, minerals and vitamins makes it an integral part of healthy and balanced diets. In recent times, meat quality perception by consumers has been negatively affected owing to its implication in the incidence of chronic diseases (WHO, 2003; WCRF, 2007). Thus, contemporary dietary guidelines advocate for a reduction in the consumption of ruminant meat (WHO, 2003; WCRF, 2007). Nevertheless, reducing meat consumption could pose severe nutritional inadequacies for some major nutrients (McAfee et al., 2010; Jiménez-Colmenero et al., 2012). Given the changes in consumers' demand, there is a need to modify the fatty acid (FA) composition of ruminant meat to improve its image and quality in order to create new market niches and preclude its loss of market share attendant on negative perceptions (JiménezColmenero et al., 2012). One major way of manipulating the FA profile of ruminant meat is via dietary oils (Nute et al., 2007; Díaz et al., 2011). Nonetheless, modifying the FA profile of ruminant meat could have negative impacts on the sensory and nutritional attributes and shelf life of the meat (Daley et al., 2007; Nute et al., 2007). For instance, enhancing the unsaturated fatty acids in meat could increase the susceptibility of such meat to lipid and protein oxidation, which could jeopardize the nutritional, physicochemical and safety attributes of the meat (Mercier et al., 1998; Nute et al., 2007; Sola-Ojo et al., 2013). Thus, enhancing the unsaturated fatty acids in ruminant meat necessitates concomitant enhancement of antioxidants to attenuate lipid and protein oxidation. Although dietary supplementation of vitamin E provides a practicable alternative 
to prevent oxidative spoilage (Lauridsen et al., 1999), the extra input cost can be recovered only if the resulting improvements in output value merit such remuneration. In addition to tocopherol and carotenoid, protective antioxidant enzymes such as glutathione peroxidase (GPx, EC 1.11.1.9), catalase (CAT, EC 1.11.1.6) and superoxide dismutase (SOD, EC 1.15.1.1) play a vital role in the regulation of oxidation of unsaturated fatty acids in a biological system (Mercier et al., 1998; Qwele et al., 2013). Supplementing PUFA and antioxidant-rich oils could be an effective strategy for precluding oxidative spoilage and enhancing PUFA and antioxidants in human diet (Kang et al., 2001). A plethora of studies has utilized various oil blends to achieve the desired FA composition in ruminant products (Kim et al., 2007; Jerónimo et al., 2009; Ferreira et al., 2014). The antioxidant properties of palm oil (Chawla \& Saxena, 2013) and the antioxidant and PUFA content of canola oil (Ghazani et al., 2014) have been espoused. Previous analyses and in vitro rumen fermentation trials (Adeyemi et al., 2015a) have utilized various combinations of canola oil and palm oil and have established that $80 \%$ canola oil and $20 \%$ palm oil gave optimum PUFA concentration and antioxidants with no deleterious effects on rumen metabolism. Similarly, a dietary blend of $80 \%$ canola oil and $20 \%$ palm oil had no effect on feed intake and growth performance in goats (Adeyemi et al., 2015c). Thus, it was proposed that blend of $80 \%$ canola oil and $20 \%$ palm oil (BCPO) would enhance the FA profile and antioxidant status and prevent oxidative spoilage in goat meat. The objective of this study was to assess the effect of a dietary blend of $80 \%$ canola oil and $20 \%$ palm oil on FA composition, antioxidant status, colour, and oxidative stability of biceps femoris muscle in goats.

\section{Materials and Methods}

The study was conducted according to the guidelines of the research policy of the Universiti Putra Malaysia on animal welfare and ethics. Twenty-four Boer bucks of $4-5$ months old, with an initial average bodyweight of $20.5 \pm 0.5 \mathrm{~kg}$, were used in the study. The feeding trial was conducted at ar-Raudhah Pty. Ltd. Kuang, Selangor, Malaysia. Animals were housed individually in wooden, slatted floor pens equipped with feeding and drinking facilities. The animals were randomly assigned to the basal diet containing on a dry matter basis, $0 \%, 4 \%$ or $8 \%$ BCPO, and fed for $100 \mathrm{~d}$ following two weeks of adaptation. The basal diet consisted of $50: 50$ forage to concentrate ratio, and the ratio was maintained for all diets. The forage portion was oil palm fronds (OPF). The concentrate consisted of $22 \%$ maize grain, $17 \%$ soybean meal, $7.5 \%$ palm kernel cake and $2 \%$ rice bran. Each of limestone, salt and mineral-vitamin premix accounted for $0.5 \%$ of the mixed diet. Ingredients in the concentrate portion were adjusted by replacing the maize grain with BCPO to make the diets isoenergetic and isonitrogenous. The diets were formulated to meet the nutritional requirements of growing goats following the recommendation of NRC (2007). The chemical composition of diets was analysed following AOAC (1990) methods. The nutrient detergent fibre (NDF) and acid detergent fibre (ADF) contents of the diet were analysed by the method of Van Soest et al. (1991). The chemical composition of the diets is shown in Table 1, and their FA composition and antioxidant contents are presented in Table 2.

Table 1 Chemical composition of dietary treatments

\begin{tabular}{lccc}
\hline \multirow{2}{*}{ Chemical composition, g/kg } & \multicolumn{3}{c}{ Levels of BCPO (\%) } \\
\cline { 2 - 4 } & 0 & $\mathbf{4}$ & $\mathbf{8}$ \\
\hline Dry matter & 677.0 & 679.0 & 680.7 \\
Crude protein, & 142.7 & 143.7 & 143.9 \\
Ether extract & 23.0 & 63.5 & 111.1 \\
Organic matter & 931.6 & 934.2 & 935.5 \\
Nitrogen free extract & 165.6 & 139.7 & 124.5 \\
Acid detergent fibre & 350.4 & 332.8 & 325.2 \\
Neutral detergent fibre & 635.2 & 626.7 & 620.6 \\
Metabolizable energy, MJ/kg DM & 11.59 & 11.61 & 11.62 \\
Calcium & 10.2 & 10.5 & 10.4 \\
Phosphorus & 5.2 & 5.4 & 5.4 \\
\hline
\end{tabular}

BCPO: blend of canola oil (80\%) and palm oil (20\%). 
Table 2 Fatty acid composition and antioxidant content of dietary treatments

\begin{tabular}{|c|c|c|c|}
\hline \multirow{2}{*}{ Parameter } & \multicolumn{3}{|c|}{ Levels of BCPO (\%) } \\
\hline & 0 & 4 & 8 \\
\hline \multicolumn{4}{|l|}{ Fatty acid (g/kg DM) } \\
\hline C12:0 & 0.01 & 0.03 & 0.04 \\
\hline C14:0 & 0.53 & 0.51 & 0.51 \\
\hline C16:0 & 2.79 & 5.98 & 7.78 \\
\hline C16:1 & 0.08 & 0.11 & 0.15 \\
\hline C18:0 & 0.56 & 1.12 & 1.43 \\
\hline C18:1n-9 & 3.82 & 14.87 & 26.32 \\
\hline C18:2w-6 & 7.05 & 11.87 & 12.06 \\
\hline C18:3w-3 & 1.06 & 2.61 & 4.13 \\
\hline n6/n3 & 6.65 & 4.55 & 2.92 \\
\hline Total FA & 15.83 & 37.09 & 52.27 \\
\hline \multicolumn{4}{|l|}{ Antioxidants (mg/kg) } \\
\hline Total carotenoid & 14.81 & 16.71 & 19.86 \\
\hline a-tocopherol & 101.12 & 112.47 & 123.21 \\
\hline y-tocopherol & 10.22 & 34.55 & 49.17 \\
\hline$\delta$-tocopherol & 1.21 & 3.45 & 5.93 \\
\hline
\end{tabular}

BCPO: blend of canola oil (80\%) and palm oil (20\%).

After the last day of the feeding trial, the animals were fasted for $12 \mathrm{~h}$ with free access to water, weighed and slaughtered according to the halal procedure as outlined in MS1500:2009 (Department of Standards Malaysia, 2009). After dressing, the carcasses were subjected to aerobic post mortem refrigerated storage $\left(4 \pm 1^{\circ} \mathrm{C}\right)$ for $7 \mathrm{~d}$. The biceps femoris muscle was sampled at the lateral face of the right hind limb on 0, 1, 4 and $7 \mathrm{~d}$ post mortem. On day $0,30 \mathrm{~g}$ of muscle cut was dissected from each carcass $(n=24)$ and divided into two portions. The first portion $(15 \mathrm{~g})$ was snap frozen and pulverized in liquid nitrogen, stored at $-80{ }^{\circ} \mathrm{C}$, and assigned to determine fatty acids, $\mathrm{pH}$, lipid and protein oxidation, antioxidants, metmyoglobin content and metmyoglobin reducing activity (MRA). The second portion (15 g) was assigned to determine drip loss. On 1, 4 and $7 \mathrm{~d}$ post mortem, $30 \mathrm{~g}$ of muscle cut was dissected from each carcass and divided into two parts. The first part $(15 \mathrm{~g})$ was assigned for the determination of colour coordinates. The biceps femoris muscle from the left hind limb was sampled on 1, 4 and $7 \mathrm{~d}$ post mortem, stored at $-80^{\circ} \mathrm{C}$ and assigned for sensory evaluation.

The $\mathrm{pH}$ of the pulverized muscles was read using a pre-calibrated portable $\mathrm{pH}$ meter (Mettler Toledo, AG 8603, Switzerland). Lipid oxidation was measured as 2-thiobarbituric acid reactive substances (TBARS) using QuantiChrom ${ }^{\text {TM }}$ TBARS Assay Kit (DTBA-100, BioAssay Systems, USA) following the manufacturer's procedure. Protein thiol was quantified according to Elman's method using 2,2-dithiobis (5-nitropyridine) DTNP (Winterbourn, 1990) modified by Morzel et al. (2006). The thiol results were expressed as $\mathrm{nmol} / \mathrm{mg}$ protein. The carbonyl content in muscles was determined using Cayman protein carbonyl colorimetric assay kit (10005020), following the manufacturer's procedure. Carbonyl content was expressed as $\mathrm{nmol} / \mathrm{mg}$ protein.

Meat colour coordinates were determined using a Colour Flex spectrophotometer (Hunter Lab Reston, $\mathrm{Va}$, USA) based on the International Commission on Illumination (CIE) LAB values (also known as lightness $\left(L^{*}\right)$, redness $\left(a^{*}\right)$ and yellowness $\left.\left(b^{*}\right)\right)$, with a $D_{65}$ illuminant and 10 standard observer tristimulus values $(X, Y, Z)$ and reflectance at specific wavelength $(400-700) \mathrm{nm}$. The device was calibrated against black and white reference tiles prior to use. The biceps femoris muscle samples of approximately $12 \mathrm{~mm}$ thickness obtained from the carcasses on 1, 4 and $7 \mathrm{~d}$ post mortem were bloomed for 30 min and placed with the bloomed surface facing the base of the colour flex cup. For each sample, three readings for $L^{*}, a^{*}$ and $b^{*}$ values were recorded and then averaged. The metmyoglobin concentration was determined as described by Krzywicki (1982). Extraction of myoglobin reductase and determination of MRA in frozen meat samples followed the procedure of Mikkelsen et al. (1999). 


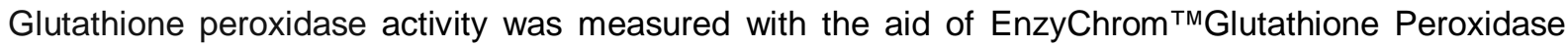
Assay Kit EGPX-100 (BioAssay Systems, USA). Super oxide dismutase activity was measured with the aid of a Cayman SOD Assay kit (Cat no 706002. Cayman Chemical), while CAT activity was measured using a Cayman Catalase Assay Kit (Cat no 707002, Cayman Chemical) following the manufacturer's procedure. The carotenoid contents in feed and muscle samples were extracted and determined following the method described by Okonkwo (2009).

Extraction of tocopherol from feed and muscle samples followed the method of Kamal-eldin et al. (2000). Quantification of tocopherol contents was done with Agilent 1200 series HPLC, as described by (Pegg \& Amarowicz, 2009).

The total FA in samples was extracted in a chloroform : methanol $(2: 1, \mathrm{v} / \mathrm{v})$ mixture in accordance to the method of Folch et al. (1967), modified by Rajion et al. (1985). The extracted fat was transmethylated to its fatty acid methyl esters (FAME) using $14 \%$ biceps femoris $_{3}$ and $0.66 \mathrm{~N} \mathrm{KOH}$ in methanol (Sigma Chemical Co., St. Louis, Mo, USA) according to the AOAC (1990) method. The FAME was separated in a gas chromatograph (Model 6890 Agilent Technologies, USA). The column used was fused silica capillary (Supelco SP-2560, $100 \mathrm{~m}, 0.25 \mathrm{~mm}$ ID, $0.20 \mathrm{~mm}$ film thickness). To facilitate optimal separation, the oven temperature was set at $100^{\circ} \mathrm{C}$ for $2 \mathrm{~min}$, and warmed to $170^{\circ} \mathrm{C}$ at $10^{\circ} \mathrm{C} / \mathrm{min}$, held for $2 \mathrm{~min}$, warmed to 230 ${ }^{\circ} \mathrm{C}$ at $5^{\circ} \mathrm{C} / \mathrm{min}$, and then held for $20 \mathrm{~min}$. The peaks of samples were identified, and concentrations were calculated based on the retention time and peak areas of known standards. A reference standard (mix C4 - C24 methyl esters; Sigma-Aldrich, Inc., St. Louis, Mo, USA) and conjugated linoleic acid (CLA) standard mixture (cis-9 trans-11 CLA and trans-10, cis-12 CLA, Sigma-Aldrich, Inc., St. Louis, Mo, USA) were used to determine recoveries and correction factors to determining individual FA composition.

The sensory evaluation was a consumer type. Assessors were drawn from staff and postgraduate students of University of Putra Malaysia. Forty-five assessors participated. The assessors were briefed on the sensory protocol and the parameters to assess using a 9-point hedonic scale (Adeyemi \& Olorunsanya, 2012b). A value of 9 indicated 'like very much' and 1 indicated 'dislike very much'. The samples were microwaved for $5 \mathrm{~min}$ at $450 \mathrm{~W}$, coded, and served to the assessors in individual booths.

The experiment followed a completely randomized design. The data were analysed by the GLM procedure of SAS (2003) in which dietary treatments, post mortem storage days and interaction between dietary treatments and post mortem days were fitted as fixed effects in repeated measure analysis of variance. Means were separated using Tukey HSD test at a significance level of $P<0.05$. Intramuscular fat (IMF) was used as a covariate for the FA composition data, but was not significant $(P<0.05)$ and thus deleted from the model.

\section{Results and Discussion}

The effects of dietary BCPO and post mortem ageing on the FA composition of biceps femoris muscle from goats are shown in Table 3, while the sums and ratios of FA in the biceps femoris muscle are presented in Table 4. The proportion of $\mathrm{C} 14: 0$ decreased $(P<0.05)$ as the level of BCPO increased in diet. This observation could be because of the reduction or inhibition of mRNA abundance and activity of lipogenic enzymes such as fatty acid synthase and acetyl coA carboxylase required to synthesize medium chain fatty acids (Kim et al., 2007). Dietary BCPO reduced $(P<0.05)$ the concentration of C15:0 in biceps femoris muscle from goats. Pentadecanoic acid (C15:0) is one of the odd chain FA derived from rumen microbes (Vlaeminck et al., 2006). Thus, the depression of C15:0 as BCPO increased in diet could be due to the effect of unprotected fat on rumen microbial ecology and metabolism by reducing the proportion of odd chain FA in microbial biomass or the flow of microbial biomass to the duodenum (Bessa et al., 2007). No changes ( $P$ $>0.05)$ were observed for the concentration of C16:0, C18:0, and C18:2n-6. The increase $(P<0.05)$ in the concentration of C18:1n-9 in the biceps femoris of oil-fed goats could be because of the increase in the intake of C18:1n-9, as demonstrated in a companion feeding trial (Adeyemi et al., 2015c). The increase in C18:1n9 could also be related to the delta-9 desaturation of 18:0 in tissues (Kim et al., 2007).

The 4\% BCPO meat had a higher $(P<0.05)$ cis-9 trans-11 CLA compared with those obtained from other treatments. The increase in CLA could be because of the partial ruminal biohydrogenation of $\mathrm{C} 18: 2 \mathrm{n}-6$ and C18:3n-3 (Bessa et al., 2007; Kim et al., 2007). The CLA could also be synthesized endogenously in the tissue by the action of $\Delta-9$ desaturase on C18:1trans-11 (Bessa et al., 2007; Kim et al., 2007). The higher cis-9 trans-11 CLA in the meat of goats fed 4\% BCPO, compared with those from goats fed $8 \%$ BCPO, was unexpected, since the concentrations of $\mathrm{C} 18: 1 \mathrm{n}-9, \mathrm{C} 18: 2 \mathrm{n}-6$ and $\mathrm{C} 18: 3 \mathrm{n}-3$ in diets and tissue $\mathrm{C} 18: 1$ trans-11 were higher in the $8 \%$ BCPO than the $4 \%$ BCPO treatment.

As found in the current study, the CLA concentration in milk increased from 10.35 to 19.42 and 32.05 $\mathrm{mg} / \mathrm{g}$ fat when Alpine does were fed $2 \%$ and $4 \%$ canola oil, respectively, but the CLA concentration tended to decrease $(29.46 \mathrm{mg} / \mathrm{g})$ when the level of canola oil increased to $6 \%$ (Mir et al., 1999). 
Table 3 Mean fatty acid composition ( $\mathrm{mg} / 100 \mathrm{~g}$ muscle) of biceps femoris muscle in goats fed graded level of blend of $80 \%$ canola oil and $20 \%$ palm oil and subjected to post mortem ageing

\begin{tabular}{|c|c|c|c|c|c|c|c|c|c|c|c|c|}
\hline \multirow{2}{*}{ Fatty acid } & \multicolumn{3}{|c|}{ Level of BCPO (\%) } & \multicolumn{6}{|c|}{ Post mortem storage (days) } & \multicolumn{3}{|c|}{$P$-value } \\
\hline & 0 & 4 & 8 & SE & 0 & 1 & 4 & 7 & SE & D & $\mathbf{T}$ & DxT \\
\hline C14:0 & 90.00 & 71.30 & 49.00 & 13.21 & 68.30 & 70.61 & 69.60 & 75.40 & 11.11 & 0.048 & 0.072 & 0.209 \\
\hline C15:0 & 110.00 & 90.50 & 71.80 & 15.42 & 81.80 & 89.12 & 83.40 & 102.01 & 10.73 & 0.035 & 0.032 & 0.419 \\
\hline C16:0 & 810.00 & 745.70 & 762.20 & 31.71 & 691.00 & 703.90 & 726.70 & 801.40 & 92.52 & 0.068 & 0.012 & 0.390 \\
\hline C16:1n-7 & 71.60 & 68.40 & 70.70 & 12.11 & 58.20 & 66.31 & 57.80 & 72.11 & 15.20 & 0.518 & 0.402 & 0.322 \\
\hline C18:0 & 607.50 & 609.20 & 659.30 & 32.00 & 541.90 & 563.32 & 577.20 & 623.61 & 67.3 & 0.206 & 0.012 & 0.562 \\
\hline C18:1n-9 & 716.00 & 794.80 & 886.10 & 60.26 & 690.60 & 693.00 & 660.60 & 714.00 & 81.44 & 0.018 & 0.920 & 0.094 \\
\hline total C18:1trans-11 & 71.60 & 68.00 & 105.30 & 16.21 & 72.21 & 77.20 & 68.60 & 75.80 & 13.00 & 0.361 & 0.213 & 0.276 \\
\hline cis-9 trans-11 CLA ${ }^{1}$ & 37.90 & 92.30 & 42.51 & 6.20 & 48.10 & 51.50 & 47.50 & 51.01 & 13.1 & 0.018 & 0.784 & 0.438 \\
\hline trans-10 cis-12 CLA & 36.10 & 40.00 & 33.10 & 6.30 & 52.90 & 59.70 & 54.60 & 56.80 & 15.11 & 0.062 & 0.540 & 0.239 \\
\hline C18:2n-6 & 586.10 & 549.10 & 518.71 & 72.1 & 492.41 & 475.50 & 449.40 & 416.00 & 72.71 & 0.065 & 0.042 & 0.647 \\
\hline C18:3n-3 & 35.80 & 38.40 & 75.20 & 1.23 & 43.80 & 42.90 & 41.00 & 40.80 & 9.40 & 0.039 & 0.039 & 0.974 \\
\hline$C 20: 4 n-6$ & 250.6 & 253.00 & 238.20 & 8.13 & 220.71 & 217.80 & 208.60 & 214.21 & 50.06 & 0.079 & 0.073 & 0.438 \\
\hline C20:5n-3 & 37.60 & 65.10 & 96.91 & 6.65 & 68.91 & 66.00 & 57.10 & 59.51 & 12.22 & 0.031 & 0.019 & 0.327 \\
\hline$C 22: 5 n-3$ & 44.00 & 81.10 & 91.90 & 8.81 & 64.10 & 64.00 & 57.80 & 58.50 & 11.06 & 0.040 & 0.007 & 0.320 \\
\hline$C 22: 6 n-3$ & 71.60 & 63.70 & 97.60 & 7.21 & 58.90 & 59.40 & 52.90 & 53.00 & 11.14 & 0.631 & 0.032 & 0.134 \\
\hline Total fatty acid & 3576.40 & 3630.60 & 3798.53 & 90.00 & 3253.00 & 3300.26 & 3212.80 & 3414.16 & 98.50 & 0.791 & 0.974 & 0.634 \\
\hline
\end{tabular}

BCPO: blend of $80 \%$ canola oil and $20 \%$ palm oil;

CLA: conjugated linoleic acid.

${ }^{1}$ cis-9, trans-11 CLA peak contains trans-7 cis-9 CLA and trans-8 cis-10 CLA;

D: diet; T: storage time; DxT: interaction between diet and storage time. 
Table 4 Mean fatty acid ratio and sums ( $\mathrm{mg} / 100 \mathrm{~g}$ muscle) of biceps femoris muscle in goats fed graded level of blend of $80 \%$ canola oil and $20 \%$ palm oil and subjected to post mortem ageing

\begin{tabular}{|c|c|c|c|c|c|c|c|c|c|c|c|c|}
\hline \multirow{2}{*}{ Parameter } & \multicolumn{3}{|c|}{ Level of BCPO (\%) } & \multicolumn{6}{|c|}{ Post mortem storage (days) } & \multicolumn{3}{|c|}{$P$-value } \\
\hline & 0 & 4 & 8 & SE & 0 & 1 & 4 & 7 & SE & D & $\mathbf{T}$ & DxT \\
\hline$\sum$ SFA & 1617.01 & 1516.81 & 1542.40 & 85.00 & 1383.21 & 1426.95 & 1497.90 & 1602.8 & 62.13 & 0.063 & 0.020 & 0.527 \\
\hline$\sum$ MUFA & 859.20 & 931.21 & 1062.20 & 25.41 & 821.10 & 836.61 & 787.20 & 861.91 & 19.78 & 0.061 & 0.219 & 0.932 \\
\hline$\sum$ PUFA & 1099.70 & 1182.71 & 1194.41 & 69.65 & 1049.91 & 1036.50 & 968.10 & 949.83 & 21.01 & 0.043 & 0.035 & 0.112 \\
\hline$\sum \omega-3$ & 189.00 & 248.32 & 361.80 & 14.17 & 235.72 & 232.00 & 208.01 & 211.81 & 10.55 & 0.010 & 0.041 & 0.098 \\
\hline$\sum \omega-6$ & 836.70 & 802.20 & 757.30 & 10.31 & 713.21 & 693.30 & 658.90 & 675.21 & 16.30 & 0.026 & 0.020 & 0.675 \\
\hline$\omega-6: \omega-3$ & 4.42 & 3.23 & 2.09 & 0.34 & 3.02 & 2.98 & 3.16 & 3.19 & 0.43 & 0.008 & 0.201 & 0.397 \\
\hline UFA : SFA & 1.21 & 1.38 & 1.47 & 0.19 & 1.34 & 1.31 & 1.20 & 1.12 & 0.23 & 0.089 & 0.050 & 0.265 \\
\hline PUFA : SFA & 0.68 & 0.77 & 0.77 & 0.06 & 0.75 & 0.73 & 0.66 & 0.58 & 0.04 & 0.016 & 0.048 & 0.614 \\
\hline
\end{tabular}

BCPO: blend of $80 \%$ canola oil and $20 \%$ palm oil.

$\sum \mathrm{SFA}=(\mathrm{C} 14: 0+\mathrm{C} 15: 0+\mathrm{C} 16: 0+\mathrm{C} 18: 0)$

$\sum$ MUFA $=(C 16: 1+C 18: 1+C 18: 1$ trans-11 $)$

$\sum U F A=\left(C 16: 1+C 18: 1+C 18: 1\right.$ trans-11+CLA cis-9 trans-11+CLA cis-12 trans- $\left.10+\sum n-3+\sum n-6\right)$

$\sum$ PUFA $=\left(\right.$ C18:1 trans-11+ CLA cis-9 trans-11+ CLA cis-12 trans- $\left.10+\sum n-3+\sum n-6\right)$;

$\sum n-3=(C 18: 3 n-3+C 20: 5 n-3+C 22: 5 n-3+C 22: 6 n-3)$

$\sum \mathrm{n}-6=(\mathrm{C} 18: 2 \mathrm{n}-6+\mathrm{C} 20: 4 \mathrm{n}-6)$

$\mathrm{n}-6: \mathrm{n}-3=(\mathrm{C} 18: 2 \mathrm{n}-6+\mathrm{C} 20: 4 \mathrm{n}-6) \div(\mathrm{C} 18: 3 \mathrm{n}-3+\mathrm{C} 20: 5 \mathrm{n}-3+\mathrm{C} 22: 5 \mathrm{n}-3+\mathrm{C} 22: 6 \mathrm{n}-3)$;

UFA : SFA $=(\Sigma$ UFA $) / \Sigma$ SFA $),$ PUFA : SFA $=(\Sigma$ PUFA $\Sigma S F A)$. 
Table $5 \mathrm{Mean} \mathrm{pH}$, antioxidant status and lipid and protein oxidation of biceps femoris muscle in goats fed graded level of blend of $80 \%$ canola oil and $20 \%$ palm oil and subjected to post mortem ageing

\begin{tabular}{|c|c|c|c|c|c|c|c|c|c|c|c|c|}
\hline \multirow{2}{*}{ Parameter } & \multicolumn{3}{|c|}{ Level of BCPO (\%) } & \multicolumn{6}{|c|}{ Post mortem storage (days) } & \multicolumn{3}{|c|}{$P$-value } \\
\hline & 0 & 4 & 8 & SE & 0 & 1 & 4 & 7 & SE & D & $\mathbf{T}$ & DxT \\
\hline $\mathrm{pH}$ & 5.76 & 5.76 & 5.77 & 0.56 & 6.51 & 5.76 & 5.76 & 5.77 & 0.61 & 0.861 & 0.003 & 0.751 \\
\hline SOD & 2.55 & 2.55 & 2.76 & 0.19 & 2.65 & 3.01 & 2.66 & 2.46 & 0.15 & 0.649 & 0.984 & 0.366 \\
\hline CAT & 1652.9 & 1693.5 & 1615.2 & 58.20 & 1654.9 & 1431.2 & 1635.0 & 1667.2 & 53.5 & 0.671 & 0.658 & 0.449 \\
\hline GPx & 82.33 & 80.66 & 76.85 & 10.11 & 80.45 & 75.47 & 88.74 & 75.86 & 8.99 & 0.888 & 0.468 & 0.139 \\
\hline Total carotenoid (mg/kg) & 0.24 & 0.26 & 0.29 & 0.07 & 0.30 & 0.25 & 0.20 & 0.18 & 0.08 & 0.142 & 0.030 & 0.099 \\
\hline a-tocopherol (mg/kg) & 2.46 & 3.38 & 4.02 & 0.26 & 3.45 & 3.24 & 2.92 & 2.90 & 0.30 & 0.001 & 0.023 & 0.101 \\
\hline y-tocopherol (mg/kg) & 0.47 & 0.77 & 0.98 & 0.08 & 1.02 & 0.93 & 0.85 & 0.80 & 0.06 & 0.001 & 0.008 & 0.243 \\
\hline$\delta$-tocopherol (mg/kg) & 0.06 & 0.08 & 0.08 & 0.01 & 0.07 & 0.07 & 0.05 & 0.03 & 0.01 & 0.196 & 0.010 & 0.311 \\
\hline TBARS (mg MDA/ kg) & 0.75 & 0.71 & 0.65 & 0.03 & 0.70 & 0.73 & 0.78 & 0.84 & 0.04 & 0.054 & 0.044 & 0.146 \\
\hline Carbonyl $^{1}$ & 1.41 & 1.37 & 1.35 & 0.10 & 1.40 & 1.81 & 2.45 & 3.04 & 0.12 & 0.982 & 0.032 & 0.145 \\
\hline Free thiol $^{1}$ & 50.15 & 52.22 & 51.16 & 4.23 & 54.22 & 52.00 & 48.01 & 40.20 & 4.77 & 0.231 & 0.001 & 0.351 \\
\hline
\end{tabular}

BCPO: blend of $80 \%$ canola oil and $20 \%$ palm oil;

SOD: superoxide dismutase activity is expressed as the amount of enzyme needed to inhibit $50 \%$ dismutation of the superoxide radical

CAT: catalase activity is expressed as nmol. $\mathrm{H}_{2} \mathrm{O}_{2} / \mathrm{min} / \mathrm{mg}$ protein;

GPx: glutathione peroxidase activity is expressed as nmoles NADPH oxidized $/ \mathrm{min} / \mathrm{mg}$ protein;

${ }^{1}$ expressed as $\mathrm{nmol} / \mathrm{mg}$ protein;

D: diet; T: storage time DxT: interaction between diet and storage time. 
The 8\% BCPO meat had a higher C18:3n-3 concentration compared with those obtained from other treatments. This was probably a result of greater intake (Adeyemi et al., 2015c) and lower extent of biohydrogenation of C18:3n-3 (Adeyemi et al., 2015a) associated with the effect of unprotected fats on rumen microbial ecology and metabolism. This finding is consistent with that of Lauridsen et al. (1999), who observed that pigs fed rapeseed oil had a higher muscle C18:3n-3 concentration compared with those fed the basal diet. Similar results were expected for C18:2n-6; however, this was not the case. Similarly, Mir et al. (1999) did not observe significant changes in C18:2n-6 concentration in milk from Alpine does supplemented with canola oil.

The concentrations of C22:5n-3 in the biceps femoris of goats fed $4 \%$ and $8 \%$ BCPO were higher $(P$ $<0.05)$ than that of the control goats. Similarly, the concentration of $C 20: 6 n-3$ in $8 \%$ BCPO meat was higher $(P<0.05)$ compared to those obtained from goats fed other diets. Diets used in the current study were devoid of long chain n-3 PUFA (Table 2). Thus, the increase in the concentrations of C22:5n-3 and C20:6n-3 reflect the increase in muscle C18:3n-3, suggesting in vivo elongation and desaturation of C18:3n-3. This observation is consistent with that of Díaz et al. (2011), who observed that lambs fed linseed oil had higher C20:5n-3 and C22:5n-3 concentrations compared to those fed palm oil.

Total n-3 FA and PUFA/SFA increased $(P<0.05)$, while the $n 6 / n 3$ decreased as BCPO increased in the diet (Table 4). No changes $(P>0.05)$ were observed for total SFA, total PUFA, $\mathrm{n}-6$ and UFA/SFA ratio among the treatments. The increase in total n-3 FA and the decrease in $n 6 / n 3$ concentrations reflects the dietary $n-3$ FA and $n 6 / n 3$ ratio (Table 2 ). The $n 6 / n 3$ ratios of chevon observed in all treatments were within the recommended value (Department of Health, 1994). The implication of this finding is that the goat meat from the current study met contemporary dietary guidelines for fatty acids intake, regardless of diet.

Post mortem ageing increased $(P<0.05)$ the concentrations of C16:0, C18:0 and C15:0 (Table 3) and total SFA (Table 4). In contrast, the concentrations of C18:2n-6, C18:3n-3, C20:5n-3, C22:5n-3 and C22:6n3 , total n-3 and n-6 FA, total PUFA, UFA/SFA and PUFA/SFA decreased $(P<0.05)$ as post mortem storage progressed. No changes $(P>0.05)$ were observed in the concentration of individual monounsaturated fatty acids (MUFA), total MUFA, cis-9 trans-11 CLA and trans-10 cis-12 CLA throughout the $7 \mathrm{~d}$ post mortem storage. No interaction $(P>0.05)$ was observed between diet and post mortem ageing for all the fatty acids. The decrease in n-3 and n-6 FA and the increase in saturated fatty acid (SFA) as post mortem storage progressed could be due to lipid oxidation resulting from the depletion of endogenous antioxidant enzymes and antioxidant compounds after slaughter. This observation is consistent with those of Díaz et al. (2011) and Muíño et al. (2014), who observed a decrease in the concentration of n-3 and n-6 PUFA in mutton aged for 7 and 12 days, respectively.

Table 5 shows the effect of diet and post mortem ageing on antioxidant status of biceps femoris muscle in goats. Muscle $\alpha$ - and $y$-tocopherol concentrations increased $(P<0.05)$ with increasing level of dietary BCPO in diet. Diet did not affect $(P>0.05)$ the concentration of total carotenoid and $\delta$-tocopherol in the muscle. Animals cannot synthesize carotenoid and tocopherol; hence, they must be supplied in the diet. Thus, their presence in body tissues indicates dietary availability. The higher $\alpha$ - and $y$-tocopherol in the biceps femoris muscle of goats fed $4 \%$ and $8 \%$ BCPO compared with that of the control goats could be because of the increase in dietary fat in the diets. Tocopherol and carotenoids are both fat-soluble compounds. Thus, the increase in dietary fat might have improved the absorption of the antioxidant compounds from the gastrointestinal tract and its deposition in the muscle. This observation is in tandem with that of Lauridsen et al. (1999), who noted that the psoas major and longissimus dorsi muscles in pigs fed 6\% rapeseed oil had a higher $\alpha$-tocopherol concentration compared with those fed basal diet. Also, Nute et al. (2007) observed that the longissimus dorsi muscle of beef cattle fed linseed oil or protected lipid supplement (contained linseed oil, soybean oil and sunflower oil encapsulated in formaldehyde-treated protein) had a higher vitamin E concentration compared with those fed fish oil, a blend of fish oil and marine algae and a blend of protected lipid supplement and marine algae. This shows that supplementing vitamin E-rich oils in diets of livestock could elevate muscle vitamin E concentration. This provides a feasible alternative to prolonging the shelf life of meat without dietary vitamin $\mathrm{E}$ supplementation, the extra cost of which to farmers may not be compensated for by the higher price of meat. There was a reduction $(P<0.05)$ in the concentration of tocopherol and carotenoid as storage continued. This finding was expected, and it reflects the weakness of the antioxidant defence system post mortem. Similarly, the concentration of vitamin E decreased during an $8 \mathrm{~d}$ post mortem ageing of semimembranosus muscle in goats (Adeyemi et al., 2015b).

Neither diet nor post mortem ageing influenced $(P>0.05)$ antioxidant enzyme activities. The induction of antioxidant enzymes in response to oxidative stress has been established (Hirano et al., 1985). The similarity in the activities of CAT, SOD and GPx among the dietary treatments may be because of the $\alpha$ - and $\mathrm{\gamma}$-tocopherol contents in the muscle. This finding suggests that the increment in muscle $\alpha$ - and $\mathrm{y}$-tocopherol in goats fed $4 \%$ and $8 \%$ BCPO compensated for the increase in the readily oxidized n-3 PUFA in the muscles. In contrast, Renerra et al. (1999) observed that dietary rapeseed oil and soybean oil raised GPx 
and CAT activities in the pectoralis major muscle of turkeys. Menhaden oil increased antioxidant enzyme activities in the liver of mice compared with corn oil (Venkantraman et al., 1994). Nalbonne et al. (1989) also observed that salmon oil tended to increase GPx activity in the hearts of rats, compared with a lard diet. It could be inferred from these studies that unsaturated fatty acids, being unstable, often elevate antioxidant enzyme activities. This substantiates the earlier assertion that the increase in $\alpha$ - and $y$-tocopherol in the meat of goats fed $4 \%$ and $8 \%$ BCPO prevented oxidative spoilage, in spite of their higher PUFA concentrations compared with the control treatment. The stability of antioxidant enzyme activities throughout the $7 \mathrm{~d}$ post mortem storage agrees with the findings of Renerre et al. (1996), who observed that the GPx and CAT activities in beef measured on $\mathrm{d} 1$ were similar to those measured on $\mathrm{d} 8$ post mortem. In contrast, Renerre et al. (1999) observed a significant reduction in GPx and CAT activities in pectoralis major muscle of turkey as storage progressed.

Diet had no effect $(P>0.05)$ on TBARS values of biceps femoris muscle in goats. This suggests that the increase in $\alpha$ - and $y$-tocopherol in the meat of oil-fed goats was only sufficient to curb the oxidative deterioration of the enhanced PUFA content. In contrast, dietary rapeseed oil and soybean oil increased TBARS values in turkey pectoralis and sartorius muscles compared with tallow (Mercier et al., 1998). The TBARS value observed in all treatments was less than $5 \mathrm{mg} \mathrm{MDA} / \mathrm{kg}$, which is specified for abnormal flavour development in meat (Insausti et al., 2001). The increase in TBARS over storage coincides with the decrease in the concentration of tocopherols and total carotenoids. The increase in TBARS value is consistent with previous findings in which the TBARS values of refrigerated broiler meat (Adeyemi et al., 2011; 2012a; Olorunsanya et al., 2011), goat meat (Karami et al., 2011; Sabow et al., 2015a) and beef (Popova et al., 2009; Liu et al., 2015) increased as storage progressed.

Diet had no effect $(P>0.05)$ on free thiol and carbonyl contents. Post mortem storage had significant $(P<0.05)$ impact on protein oxidation. The carbonyl content increased, while the free thiol content reduced as storage progressed. This finding coincides with the decrease in the concentration of antioxidant compounds as storage progressed. The decrease in free thiol and increase in carbonyl content is an indication of protein oxidation. The thiol content reduced from 54.2 to $40.2 \mathrm{nmol} / \mathrm{mg}$ protein, representing about $26 \%$ loss. Similarly, Adeyemi et al. (2015b) observed a 21\% loss in thiol in chevon from 0 to 8 d post mortem. The formation of carbonyl is the most common indicator of oxidized proteins (Mercier et al., 1998; Popova et al., 2009). The increase in carbonyl concentration as storage progressed is in tandem with the report in beef (Popova et al., 2009) and turkey meat (Mercier et al., 1998) subjected to refrigerated storage.

The $\mathrm{pH}$ is a reliable indicator of the potential quality of meat (Adeyemi \& Sazili, 2014). Diet had no effect on muscle $\mathrm{pH}$ (Table 5). The pH observed on $\mathrm{d} 0$ (45 min post mortem) was higher than that of $\mathrm{d} 1$. This could be attributed to post mortem glycolysis, during which muscle glycogen is converted to lactic acid, thereby causing a decline in $\mathrm{pH}$ (Adeyemi \& Sazili, 2014; Salwani et al., 2015). The pH was stable from $1 \mathrm{~d}$ to $7 \mathrm{~d}$ post mortem. This indicates that post mortem glycolysis was completed by $24 \mathrm{~h}$ post mortem.

Colour is an important meat quality parameter because it is the first tool used by consumers to identify and select meat (Farouk et al., 2014; Liu et al., 2015). Diet did not affect $(P>0.05)$ colour coordinates, metmyoglobin content and MRA (Table 6). This finding was unexpected, given the increase in the concentration of $\alpha$ - and $y$-tocopherol in the meat of goats fed $4 \%$ and $8 \%$ BCPO compared with the control goats. This coincides with the similarity in TBARS value across the dietary treatments. This observation suggests a trade-off of antioxidants between the maintenance of colour/pigment stability and lipid and protein stability. Increasing post mortem storage decreased $(P<0.05) a^{*}$ and MRA, but increased $L^{*}$ and MetMb content. This observation could be because of the weakness of the antioxidant defence system, which decreased the oxidative stability of lipids, and/or myoglobin. Zakrys et al. (2008) and Adeyemi et al. (2015b) observed that changes in $\mathrm{a}^{*}$ values are related to lipid oxidation and are strongly correlated with the TBARS values. Post mortem storage did not affect $b^{\star}$ of biceps femoris muscle in goats.

Redness is the most significant colour parameter for assessing meat oxidation (Adeyemi et al., 2015b; Sabow et al., 2016). Zakrys et al. (2008) showed that instrumental $a^{*}$ value had a negative correlation, while $L^{*}$ value had a positive correlation with post mortem storage days. This suggests that samples became less red and lighter over the duration of storage (Sabow et al., 2016). The increase in $L^{*}$ value as storage progressed is in line with the report of Sabow et al. (2015b), who observed that ageing improved lightness of chevon. The decrease in redness as post mortem storage progressed could be because of the oxidation of myoglobin (deoxymyoglobin or oxymyoglobin) to form metmyoglobin owing to decreased metmyoglobin reducing activity (MRA). The increase in MetMb concentration over storage is in tandem with the findings of Liu et al. (2015), who observed an increase in the MetMb concentration of beef patties aged for $8 \mathrm{~d}$. The decrease $(P<0.05)$ in MRA over storage is consistent with the findings of Madhavi \& Carpenter (1993), who observed a reduction in MRA of beef aged for $21 \mathrm{~d}$. Contrarily, a significant increase in the MRA of beef patties over an 8-d post mortem storage was observed (Liu et al., 2015). The inconsistencies among studies over the effect of post mortem ageing on MRA of meat could be because of differences in the methodology, 
the rate of myoglobin oxidation, and the efficacy of one or more enzymes required to reduce the formed metmyoglobin (Bekhit \& Faustman, 2005).

Table 6 Mean colour coordinates, \% metmyoglobin and metmyoglobin reducing activity of biceps femoris muscle in goats fed graded level of blend of $80 \%$ canola oil and $20 \%$ palm oil and subjected to post mortem ageing

\begin{tabular}{|c|c|c|c|c|c|c|c|c|c|c|c|}
\hline \multirow{2}{*}{ Parameter } & \multicolumn{3}{|c|}{ Level of BCPO (\%) } & \multicolumn{5}{|c|}{$\begin{array}{l}\text { Post mortem storage } \\
\text { (days) }\end{array}$} & \multicolumn{3}{|c|}{$P$-value } \\
\hline & 0 & 4 & 8 & SE & 1 & 4 & 7 & SE & D & $\mathbf{T}$ & DxT \\
\hline Lightness (L*) & 34.44 & 32.23 & 32.66 & 0.50 & 31.56 & 33.37 & 35.27 & 0.59 & 0.1384 & 0.0348 & 0.016 \\
\hline Redness $\left(a^{*}\right)$ & 11.33 & 11.46 & 11.82 & 0.31 & 13.21 & 12.01 & 10.80 & 0.27 & 0.801 & $<.0001$ & 0.236 \\
\hline Yellowness (b*) & 13.91 & 13.38 & 12.98 & 0.32 & 14.86 & 14.44 & 15.09 & 0.31 & 0.512 & 0.128 & 0.106 \\
\hline$\%$ Metmyoglobin & 8.22 & 7.68 & 7.77 & 1.44 & 5.01 & 8.29 & 10.42 & 3.12 & 0.222 & $<.0001$ & 0.441 \\
\hline $\begin{array}{l}\text { MRA } \\
(\mathrm{nmol} / \mathrm{min} / \mathrm{g})\end{array}$ & 178.1 & 182.3 & 185.6 & 8.97 & 180.2 & 178.1 & 170.6 & 10.22 & 0.516 & 0.021 & 0.354 \\
\hline
\end{tabular}

BCPO: blend of $80 \%$ canola oil and $20 \%$ palm oil;

D: diet; T: storage time. DxT: interaction between diet and storage time;

MRA: metmyoglobin reducing activity.

Diet had no effect on consumers' perception of tenderness, juiciness, flavour and overall acceptability of goat meat (Table 7). This finding is in tandem with that of Santos-Silva et al. (2004), who found that supplementation with soybean oil did not affect the sensory attributes of lamb meat. Post mortem storage did not affect sensory attributes of goat meat. However, the tenderness score tended $(P>0.05)$ to increase as storage progressed.

Table 7 Mean sensory score of biceps femoris muscle from goats fed graded level of blend of $80 \%$ canola oil and $20 \%$ palm oil and subjected to post mortem ageing

\begin{tabular}{|c|c|c|c|c|c|c|c|c|c|c|c|}
\hline \multirow{2}{*}{ Parameter } & \multicolumn{3}{|c|}{ Level of BCPO (\%) } & \multicolumn{5}{|c|}{$\begin{array}{l}\text { Post mortem storage } \\
\text { (days) }\end{array}$} & \multicolumn{3}{|c|}{$P$-value } \\
\hline & 0 & 4 & 8 & SE & 1 & 4 & 7 & SE & D & $\mathbf{T}$ & DXT \\
\hline Juiciness & 6.98 & 7.20 & 7.01 & 0.40 & 6.56 & 7.11 & 6.98 & 0.11 & 0.221 & 0.812 & 0.221 \\
\hline Tenderness & 6.52 & 6.54 & 6.50 & 0.73 & 6.50 & 6.66 & 7.21 & 0.71 & 0.112 & 0.062 & 0.609 \\
\hline Flavour & 7.01 & 7.10 & 6.99 & 0.65 & 7.11 & 7.34 & 7.19 & 0.14 & 0.152 & 0.708 & 0.162 \\
\hline Overall acceptability & 7.22 & 7.00 & 7.12 & 0.88 & 6.50 & 6.72 & 7.00 & 0.47 & 0.213 & 0.091 & 0.312 \\
\hline
\end{tabular}

BCPO: blend of $80 \%$ canola oil and $20 \%$ red palm oil.

$\mathrm{D}$ : diet; $\mathrm{T}$ : storage time; DxT: interaction between diet and storage time.

\section{Conclusion}

The results of the current study indicate that supplementing a blend of $80 \%$ canola oil and $20 \%$ palm oil in goats' diets produced CLA and n-3 PUFA enriched chevon. Dietary BCPO did not affect colour, metmyoglobin and oxidative stability of lipid and protein of goat meat. Post mortem ageing decreased $n-3$ and n-6 PUFA and antioxidant compounds and increased the SFA. Lipid and protein oxidation, meat redness and metmyoglobin-reducing activity decreased, while metmyoglobin content increased as post mortem storage progressed. Neither diet nor post mortem ageing influenced antioxidant enzyme activities. Further study is suggested to characterize flavour compounds, fatty acids and quality attributes of other muscles as influenced by dietary BCPO and post mortem ageing. 


\section{Acknowledgements}

The authors thank the management and staff of ar-Raudhah Biotech Farm Pty Ltd. for giving them the opportunity to conduct the feeding trial using the facilities on the farm. They appreciate the technical assistance rendered by Lydia, Cahyatrianti, Rabizah Ibrahim and Priyono Priyono.

\section{Authors' contributions}

KDA, RK, MI and AQS conceived the idea. KDA, AQS, RMS, MI, ME and ABS did the meat quality, fatty acid and antioxidant analysis. KDA, RK and RMS did the sensory analysis. KDA prepared the manuscript and did the statistical analysis. All authors read and approved the manuscript.

\section{Conflict of interest}

The authors declare that they have no conflict of interest.

\section{References}

Adeyemi, K.D., Olorunsanya, A.O. \& Akanji, M.A., 2011. Effect of watermelon (Citrulus lantus) extracts on oxidative stability of broiler meat. Afr. J. Gen. Agric. 7, 103-108.

Adeyemi, K.D. \& Olorunsanya, O.A., 2012a. Comparative analysis of phenolic composition and antioxidant effect of four cowpea (Vignia unguiculata) seed coat extracts on broiler meat. Iran. J. Appl. Anim. Sci. 2,343-349.

Adeyemi, K.D. \& Olorunsanya, A.O., 2012b. Effect of tomato (Lycopersicon esculentum) powder on oxidative stability and sensory characteristics of broiler meat. Afr. J. Food Agric. Nutr. Dev. 12, 6794-6808.

Adeyemi, K.D. \& Sazili A.Q., 2014. Efficacy of carcass electrical stimulation in meat quality enhancement: A review. Asian Austral. J. Anim. Sci. 27, 447-456.

Adeyemi, K.D., Ebrahimi M., Samsudin, A.A., Alimon, A.R., Karim, R., Karsani, S.A. \& Sazili, A.Q., 2015a. Influence of Carotino oil on in vitro rumen fermentation, metabolism and apparent biohydrogenation of fatty acids. Anim. Sci. J. 86, 270-278.

Adeyemi, K.D., Sabow, A.B., Shittu, R.M., Karim, R., Karsani, S.A. \& Sazili, A.Q. 2015b. Impact of chill storage on antioxidant status, lipid and protein oxidation, color, drip loss and fatty acids of semimembranosus muscle in goats. CyTA. J. Food. doi: 10.1080/19476337.2015.1114974.

Adeyemi, K.D., Sazili, A.Q., Ebrahimi M, Samsudin, A.A., Alimon, A.R., Karim, R., Karsani, S.A. \& Sabow, A.B., 2015c. Effects of blend of canola oil and palm oil on nutrient intake and digestibility, growth performance, rumen fermentation and fatty acids in goats. Anim. Sci. J. doi: 10.1111/asj.12549.

AOAC, 1990. Official Methods of Analysis. (15th ed.). Arlington, VA: Association of Official Analytical Chemists. $931-932$ pp.

Bekhit, A. \& Faustman, C., 2005. Metmyoglobin reducing activity. Meat Sci. 71, 407-439.

Bessa, R.J., Alves, S.P., Jerónimo, E., Alfaia, C.M., Prates, J.A. \& Santos-Silva, J., 2007. Effect of lipid supplements on ruminal biohydrogenation intermediates and muscle fatty acids in lambs. Eur. J. Lipid Sci. Technol. 109, 868-878.

Chawla, S. \& Saxena, S., 2013. Red palm oil-health benefits and their molecular executors. Int J Bioassay. 2 , 1223-1231.

Daly, C., Moloney, A. \& Monahan, F., 2007. Lipid and colour stability of beef from grazing heifers supplemented with sunflower oil alone or with fish oil. Meat Sci. 77, 634-642.

Department of Health, 1994. Report on health and social subjects. No. 46. Nutritional Aspects of Cardiovascular Disease. London: HMSO.

Department of Standards, Malaysia. 2009. MS1500:2009: Halal food production, preparation, handling and storageGeneral guidelines (second revision) Malaysia.

Díaz, M., Cañeque, V., Sánchez, C., Lauzurica, S., Pérez, C., Fernández, C., Álvarez, I. \& De la Fuente, J., 2011. Nutritional and sensory aspects of light lamb meat enriched in $n-3$ fatty acids during refrigerated storage. Food Chem. 124, 147-155.

Farouk, M.M., Al-Mazeedi, H.M., Sabow, A.B., Bekhit, A.E.D., Adeyemi, K.D., Sazili, A.Q. \& Ghani, A., 2014. Halal and Kosher slaughter methods and meat quality: A review. Meat Sci. 98, 505-519.

Ferreira E., Pires, A., Susin, I., Gentil, R., Parente, M., Nolli, C., Meneghini, R., Mendes, C. \& Ribeiro, C., 2014. Growth, feed intake, carcass characteristics, and meat fatty acid profile of lambs fed soybean oil partially replaced by fish oil blend. Anim. Feed Sci. Technol. 18, 9-18.

Folch, J., Lees, M. \& Sloane-Stanley, G., 1957. A simple method for the isolation and purification of total lipids from animal tissues. J. Biol. Chem. 226, 497-509.

Ghazani, S.M., García-Llatas, G. \& Marangoni, A.G., 2014. Micronutrient content of cold-pressed, hot-pressed, solvent extracted and RBD canola oil: Implications for nutrition and quality. Eur. J. Lipid. Sci. Technol. 116, 380-387.

Hirano, K., Fukuta, M., Adachi, T., Hayashi, K., Sugiura, M., Mori, Y. \& Toyoshi, K., 1985. In vitro synthesis of superoxide dismutases of rat liver. Biochem. Bioph. Res. Co. 129, 89-94.

Insausti, K., Beriain, M., Purroy, A., Alberti, P., Gorraiz, C. \& Alzueta, M., 2001. Shelf life of beef from local Spanish cattle breeds stored under modified atmosphere. Meat Sci. 57, 273-281.

Jerónimo, E., Alves, S.P., Prates, J.A., Santos-Silva, J. \& Bessa, R.J., 2009. Effect of dietary replacement of sunflower oil with linseed oil on intramuscular fatty acids of lamb meat. Meat Sci. 83, 499-505.

Jiménez-Colmenero, F., Herrero, A., Cofrades, S. \& Ruiz-Capillas, C., 2012. Meat and Functional Foods. In: Handbook of Meat and Meat Processing. Ed: Hui, Y.H., CRC press. 225 pp. 
Kamal-Eldin., A., Frank, J., Razdan, A., Tengblad, S., Basu, S. \& Vessby, B., 2000. Effects of dietary phenolic compounds on tocopherol, cholesterol, and fatty acids in rats. Lipid 35, 427-435.

Kang, K.R., Cherian, G. \& Sim, J.S., 2001. Dietary palm oil alters the lipid stability of polyunsaturated fatty acid-modified poultry products. Poult. Sci. 80, 228-234.

Karami, M., Alimon, A.R., Sazili, A.Q., Goh, Y.M. \& Ivan, M., 2011. Effects of dietary antioxidants on the quality, fatty acid profile, and lipid oxidation of longissimus muscle in Kacang goat with aging time. Meat Sci. 88, 102-108.

Kim, S., Adesogan, A., Badinga, L. \& Staples, C., 2007. Effects of dietary n-6: n-3 fatty acid ratio on feed intake, digestibility, and fatty acid profiles of the ruminal contents, liver, and muscle of growing lambs. J. Anim. Sci. 85, 706-716.

Krzywicki, K., 1982. The determination of haem pigments in meat. Meat Sci. 7, 29-36.

Lauridsen, C., Nielsen, J.H., Henckel, P. \& Sørensen, M.T., 1999. Antioxidative and oxidative status in muscles of pigs fed rapeseed oil, vitamin E and copper. J. Anim. Sci. 77, 105-115.

Liu, F., Xu, Q., Dai, R. \& Ni, Y., 2015. Effects of natural antioxidants on colour stability, lipid oxidation and metmyoglobin reducing activity in raw beef patties. Acta Sci. Pol. Technol. Aliment. 14, 37-44.

Madhavi, D. \& Carpenter, C.E., 1993. Aging and processing affect colour, metmyoglobin reductase and oxygen consumption of beef muscles. J. Food Sci. 58, 939-942.

McAfee, A.J., McSorley, E.M., Cuskelly, G.J., Moss, B.W., Wallace, J.M., Bonham, M.P. \& Fearon, A.M., 2010. Red meat consumption: An overview of the risks and benefits. Meat Sci. 84, 1-13.

Mercier, Y., Gatellier, P., Viau, M., Remignon, H. \& Renerre, M., 1998. Effect of dietary fat and vitamin E on colour stability and on lipid and protein oxidation in turkey meat during storage. Meat Sci. 48, 301-318.

Mikkelsen, A., Juncher, D. \& Skibsted, L.H., 1999. Metmyoglobin reductase activity in porcine m. longissimus dorsi. Meat Sci. 51, 155-161.

Mir, Z., Goonewardene, L.A., Okine, E., Jaegar, S. \& Scheer, H.D., 1999. Effect of feeding canola oil on constituents, conjugated linoleic acid (CLA) and long chain fatty acids in goat milk. Small Rumin. Res. 33, 137-143.

Morzel, M., Gatellier, P., Sayd, T., Renerre, M. \& Laville, E., 2006. Chemical oxidation decreases proteolytic susceptibility of skeletal muscle myofibrillar proteins. Meat Sci. 73, 536-543.

Muíño, I., Apeleo, E., de la Fuente, J., Pérez-Santaescolástica, C., Rivas-Cañedo, A., Pérez, C., Díaz, M.T., Cañeque, V. \& Lauzurica, S., 2014. Effect of dietary supplementation with red wine extract or vitamin $\mathrm{E}$ in combination with linseed and fish oil on lamb meat quality. Meat Sci. 98, 116-123.

Nalbone, G., Leonardi, J., Termine, E., Portugal, H., Lechene, P., Pauli A. \& Lafonf, H., 1989. Effects of fish oil, corn oil and lard diets on lipid peroxidation status and glutathione peroxidase activities in rat heart. Lipid 24, 179-186.

NRC, 2007. Nutrient Requirements of Small Ruminants. Natl. Acad. Press. Washington, DC., USA.

Nute, G., Richardson, R., Wood, J., Hughes, S., Wilkinson, R., Cooper, S. \& Sinclair, L., 2007. Effect of dietary oil source on the flavour and the colour and lipid stability of lamb meat. Meat Sci. 77, 547-555.

Okonkwo, J., 2009. Effects of breed and storage duration on the beta-carotene content of egg yolk. Pak. J. Nutr. 8, 1629-1630.

Olorunsanya, A.O., Adeyemi, K.D. \& Babatunde, I.A., 2011. Effect of bamboo (Bambusa valgaris) and elephant grass (Pennisetum purpureum) leaf extracts on oxidative stability of cooked and raw broiler meat. J. Agr. Res. Dev. 10, 1-10.

Pegg, R.B. \& Amarowicz, R., 2009. Content of tocopherol isomers in oilseed radish cultivars - a short report. Pol. J. Food. Nutr. Sci. 59, 129-133.

Popova, T., Marinova, P., Vasileva, V., Gorinov, Y. \& Lidji, K., 2009. Oxidative changes in lipids and proteins in beef during storage. Arch. Zootech. 3, 30-38.

Qwele, K., Hugo, A., Oyedemi, S., Moyo, B., Masika, P. \& Muchenje, V., 2013. Chemical composition, fatty acid content and antioxidant potential of meat from goats supplemented with Moringa (Moringa oleifera) leaves, sunflower cake and grass hay. Meat Sci. 93, 455-462.

Rajion, M., McLean, J. \& Cahill, R.N., 1985. Essential fatty acids in the fetal and newborn lamb. Aust. J. Biol. 38, 33-40.

Renerre, M., Dumont, F. \& Gatellier, P., 1996. Antioxidant enzyme activities in beef in relation to oxidation of lipid and myoglobin. Meat Sci. 43,111-121.

Renerre, M., Poncet, K., Mercier, Y., Gatellier, P. \& Métro, B., 1999. Influence of dietary fat and vitamin E on antioxidant status of muscles of turkey. J. Agric. Food Chem. 47, 237-244.

Sabow, A.B., Sazili, A.Q., Zulkifli, I., Goh, Y.M., Ab Kadir, M.Z.A., Abdulla, N., Nakyinsige, K., Kaka, U. \& Adeyemi, K.D., 2015a. A comparison of bleeding efficiency, microbiological quality and lipid oxidation in goats subjected to conscious halal slaughter and slaughter following minimal anesthesia. Meat Sci. 104, 78-84.

Sabow, A.B., Sazili, A.Q., Zulkifli, I., Goh, Y.M., Ab Kadir, M.Z.A. \& Adeyemi, K.D., 2015b. Physico-chemical characteristics of longissimus lumborum muscle in goats subjected to halal slaughter and anesthesia (halothane) pre-slaughter. Anim. Sci. J. doi: 10.1111/asj.12385.

Sabow, A.B., Sazili, A.Q., Aghwan, A.A., Zulkifli, I., Goh, Y.M., Ab Kadir, M.Z.A., Nakyinsige, K., Kaka, U. \& Adeyemi, K.D., 2016. Changes of microbial spoilage, lipid-protein oxidation and physicochemical properties during postmortem refrigerated storage of goat meat. Anim. Sci. J. doi: 10.1111/asj.12496.

Salwani, M.S., Adeyemi, K.D., Sarah, S.A., Vejayan J., Zulkifli, I. \& Sazili, A.Q., 2015. Skeletal muscle proteome and meat quality of broiler chickens subjected to gas stunning prior slaughter or slaughtered without stunning. CyTA. J. Food. doi: 10.1080/19476337.2015.1112838.

Santos-Silva, J., Mendes, I., Portugal, P. \& Bessa, R., 2004. Effect of particle size and soybean oil supplementation on growth performance, carcass and meat quality and fatty acid composition of intramuscular lipids of lambs. Livest. Prod. Sci. 90, 79-88. 
SAS, 2003. Statistical Analysis Systems users' guide (version 9.1.) SAS Institute Inc. Cary, NC., USA.

Sola-Ojo, F.E., Adeyemi, K.D., Toye, A.A., Bolu, S.A., Fayeye, T.R., Annongu, A., Garba, S.O. \& Karim, R.O., 2013. Performance, carcass profile and oxidative stability of broiler chickens fed processed baobab seed meal. Bull Environ. Pharmaco. Life Sci. 2, 94-99.

Van Soest, P.V., Robertson, J. \& Lewis, B., 1991. Methods for dietary fiber, neutral detergent fiber, and nonstarch polysaccharides in relation to animal nutrition. J. Dairy Sci. 74, 3583-3597.

Venkatraman, J.T., Chandrasekar, B., Dai Kim, J. \& Fernandes, G., 1994. Effects of n-3 and n-6 fatty acids on the activities and expression of hepatic antioxidant enzymes in autoimmune-prone NZB× NZW F1 mice. Lipid 29, 561-568.

Vlaeminck, B., Fievez, V., Cabrita, A., Fonseca, A. \& Dewhurst, R., 2006. Factors affecting odd-and branched-chain fatty acids in milk: A review. Anim. Feed Sci. Technol. 131, 389-417.

Winterbourn, C.C., 1990. Oxidative reactions of hemoglobin. Meth. Enzym. 186, 265.

World Health Organization, 2003. Diet, nutrition and the prevention of chronic diseases. WHO Technical Report Series. 916, 1-60.

World Cancer Research Fund/American Institute for Cancer Research, 2007. Food, nutrition, physical activity and the prevention of cancer: A global perspective. Washington, DC: AICR.

Zakrys, P., Hogan, S., O'Sullivan, M., Allen, P. \& Kerry, J., 2008. Effects of oxygen concentration on the sensory evaluation and quality indicators of beef muscle packed under modified atmosphere. Meat Sci. 79, 648-655. 